\title{
Making a choice: initial fraction of inspired oxygen for resuscitation at birth of a premature infant less than 32 weeks gestational age
}

This article was published in the following Dove Press journal:

Research and Reports in Neonatology

3I January 2014

Number of times this article has been viewed

\section{Gregory P Moore ${ }^{1-3}$ \\ Behdad Navabi ${ }^{2}$}

'Department of Pediatrics, Division of Neonatology, Children's Hospital of Eastern Ontario, ${ }^{2}$ Department of Obstetrics and Gynecology, Division of Newborn Care, The Ottawa Hospital General Campus, ${ }^{3}$ Department of Pediatrics, University of Ottawa, Ottawa, ON, Canada
Correspondence: Gregory P Moore

The Ottawa Hospital, General Campus, Division of Newborn Care,

Box 806, 50I Smyth Road, Ottawa,

ON, Canada KIH 8L6

$\mathrm{Tel}+\mathrm{I} 613737856$ I

Fax + I 6137378889

Email gmoore@cheo.on.ca

\section{Dear editor}

As briefly noted by Abdel-Hady and Nasef in their 2012 publication in Research and Reports in Neonatology, ${ }^{1}$ the best initial fraction of inspired oxygen $\left(\mathrm{FiO}_{2}\right)$ to use during resuscitation of preterm neonates $<32$ weeks gestational age (GA) has not been clearly elucidated. Most recent neonatal resuscitation guidelines leave the difficult choice of the actual $\mathrm{FiO}_{2}$ in the hands of individual physicians. We believe that this letter, through review and discussion of the recent published literature, will aid physicians in this choice and confirm that, as per the opinion of Abdel-Hady and Nasef, the best present evidence-based choice for the initial $\mathrm{FiO}_{2}$ for resuscitating preterm infants $<32$ weeks GA appears to be $30 \%$. However, determination of the ideal initial resuscitation gas requires further research assessing both short-term and long-term outcomes.

The common clinical scenario of attending the birth of a premature infant brings up an important clinical question: in an infant born at $<32$ weeks GA (population), does the use of a low level of oxygen ( $\leq 30 \%$, intervention) instead of a high level of oxygen ( $\geq 90 \%$, comparison) as the initial $\mathrm{FiO}_{2}$ for resuscitation result in adequate stabilization (outcome)? In order to answer this question, we sought recent randomized controlled trials (RCTs) examining the desired patient population, intervention, comparison, and outcome. We performed a PubMed search covering January 2008 until October 2013 using the following keywords: "oxygen" AND "resuscitation" AND "premature infant". Limits were: human species, English language, and age from birth to 23 months. Publications prior to January 2008 were excluded because of redundancy, lack of applicability, or outdated information being likely in these publications. We examined personal files and reference listings of the full-text articles for any additional publications. Our search yielded a total of 141 titles. We reviewed 44 abstracts and retrieved 21 full-text articles or conference proceedings for detailed review. We found four relevant $\mathrm{RCTs}^{2-5}$ from the search and one additional RCT from our gray $\operatorname{search}^{6}$ (Table 1).

\section{Discussion}

Term neonates and premature neonates born at $\geq 32$ weeks GA should be resuscitated with room air in nearly all circumstances, ${ }^{7}$ while there is no consensus on the ideal $\mathrm{FiO}_{2}$ for resuscitation of preterm infants $<32$ weeks. ${ }^{7-10}$ However, as recently as 2005, 


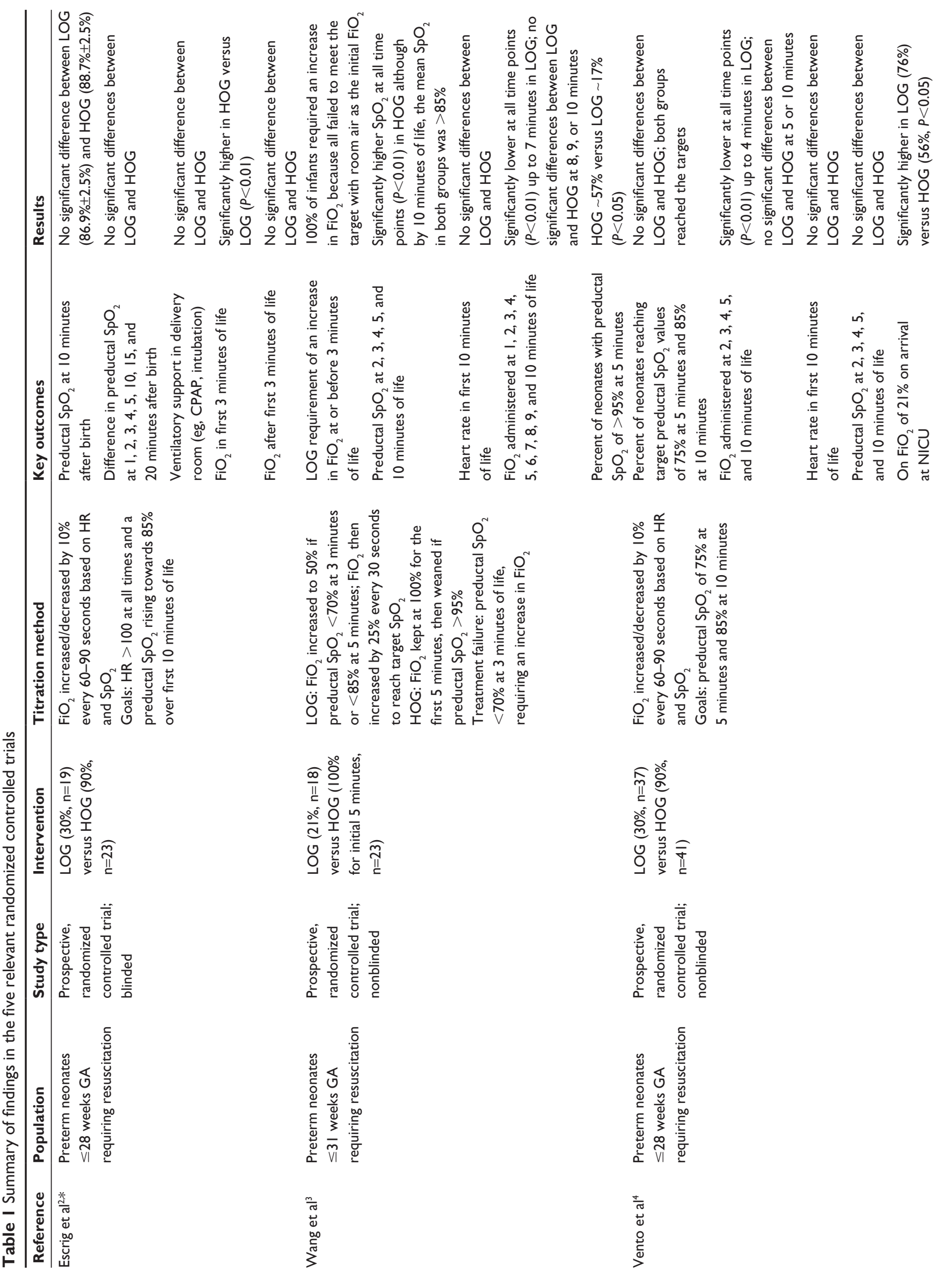




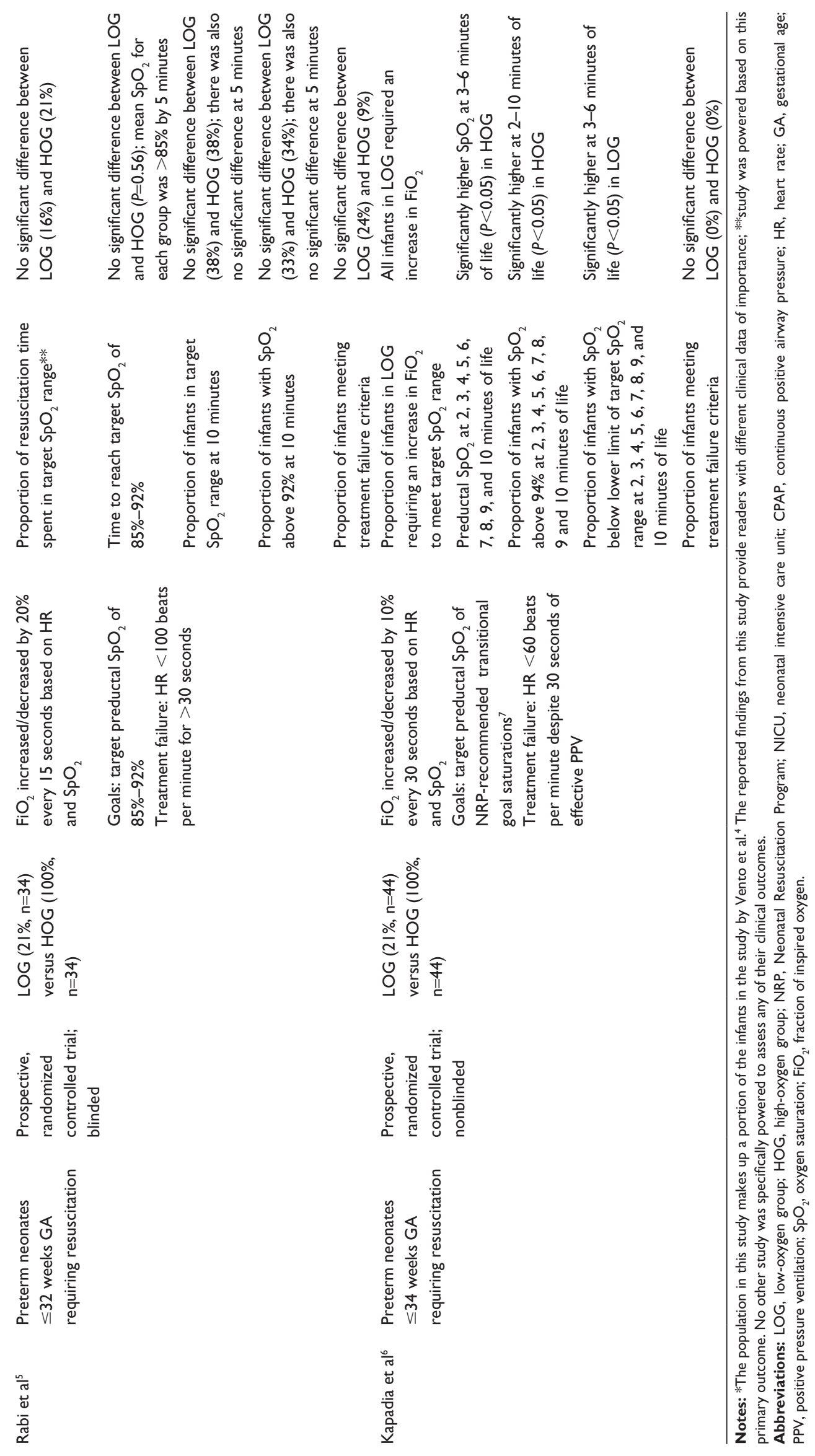


virtually all resuscitations for extremely low birth weight infants in the USA used $100 \%$ oxygen. ${ }^{9}$

The International Liaison Committee on Resuscitation (ILCOR) has stated that the initial use of room air or $100 \%$ oxygen is more likely to result in hypoxemia or hyperoxia, respectively, than initiation of resuscitation with $30 \%$ or $90 \%$ oxygen for preterm infants $<32$ weeks GA. ILCOR also recommends that resuscitation be performed with judicious use of blended oxygen and room air, ideally guided by pulse oximetry. Notably, the ILCOR ${ }^{8}$ and American Heart Association recommendations ${ }^{11}$ did not include the published results of three RCTs found in Table $1^{4-6}$ due to their more recent publication dates. A recent meta-analysis outlines the limitations of the current data around the topic, ${ }^{12}$ but does not provide clinicians with a practical conclusion on how to presently manage the use of oxygen in these resuscitations.

The science around this issue is evolving. A high $\mathrm{FiO}_{2}$ leads to production of free radicals with the potential to extensively damage human cells. ${ }^{13} \mathrm{~A}$ high $\mathrm{FiO}_{2}$ may prolong time to spontaneous crying and breathing, increase oxygen consumption, decrease minute ventilation, cause atelectasis, or decrease cerebral blood flow. ${ }^{13,14}$ At the same time, an overly low $\mathrm{FiO}_{2}$ may result in various types of organ dysfunction, including neonatal encephalopathy. ${ }^{13}$ The result of these data is physician uncertainty as to what is best for the premature infant they are resuscitating.

The determination of an appropriate oxygen saturation $\left(\mathrm{SpO}_{2}\right)$ target below which oxygen therapy does more good than harm during resuscitation of premature infants remains elusive; the highest safe $\mathrm{SpO}_{2}$ remains unclear as well. ${ }^{15}$ Preterm infants take longer than term infants to reach an $\mathrm{SpO}_{2}$ of $>85 \%{ }^{16,17}$ Dawson et al report on $\mathrm{SpO}_{2}$ levels in term and preterm infants (including 39 infants born at $<32$ weeks GA) that could guide post-delivery changes in the $\mathrm{F}_{\mathrm{i}} \mathrm{O}_{2}$, but the infants studied were those that required no oxygen or assisted ventilation in the minutes after birth; ${ }^{18}$ therefore, the reported $\mathrm{SpO}_{2}$ levels may not be best for preterm infants of $<32$ weeks GA who actually require resuscitation. That said, these levels are recommended by the American Academy of Pediatrics' guideline for use when resuscitating even preterm babies, ${ }^{7}$ and the European Resuscitation Council does not provide clearly recommended saturation targets for the preterm infant $<32$ weeks GA. ${ }^{19,20}$ Based on a review of several publications, Finer and Rich $^{14}$ recommend: "initial $\mathrm{SpO}_{2}$ following delivery can be assumed to be around 50\% and increases by 5 to $6 \%$ per min for the very preterm infant. This will result in an $\mathrm{SpO}_{2}$ of 65 to $70 \%$ at $3 \mathrm{~min}, 75$ to $80 \%$ at $5 \mathrm{~min}$ and 85 to $90 \%$ by 7 to $8 \mathrm{~min}$ of age." All RCTs we reviewed (Table 1) considered an $\mathrm{SpO}_{2}$ of $\geq 85 \%$ at 10 minutes acceptable, although one targeted an $\mathrm{SpO}_{2}$ of $\geq 85 \%$ at 5 minutes in their low-oxygen group while accepting notably higher $\mathrm{SpO}_{2}$ readings of $>95 \%$ in the first 5 minutes of life in their high-oxygen group, ${ }^{3}$ and one targeted an $\mathrm{SpO}_{2}$ of $85 \%-92 \%$ as soon as $\mathrm{SpO}_{2}$ readings were available, ${ }^{5}$ which is usually by $1-2$ minutes of life. Although the final determination of the ideal $\mathrm{SpO}_{2}$ targeting remains elusive, an $\mathrm{SpO}_{2}$ of $85 \%-94 \%$ at 10 minutes seems to be considered acceptable by most experts.

Table 1 details the few small RCTs that compare commencing with a low $\mathrm{FiO}_{2}(21 \%-30 \%)$ versus high $\mathrm{FiO}_{2}$ $(90 \%-100 \%)$ during resuscitation of preterm infants (particularly those $\leq 31$ weeks GA). One RCT likely had a single 32-week GA infant based on their inclusion of preterm neonates $\leq 32$ weeks and their final population having a mean GA of 29 (95\% confidence interval 28-30); another included infants at 32-34 weeks GA. ${ }^{6}$ Various titration methods were used (see Table 1 for details); of note, sudden $\mathrm{FiO}_{2}$ alterations (over $10 \%$ every 30 seconds) may result in constriction of the pulmonary vasculature. ${ }^{4}$ In the two RCTs ${ }^{2,4}$ comparing $30 \%$ versus $90 \%$ as the starting $\mathrm{FiO}_{2}$ in infants $\leq 28$ weeks GA, saturations were similar in both groups at all times, but the high-oxygen group had greater exposure to oxygen, ${ }^{2}$ more signs of oxidative stress, more ventilation days, and prolonged oxygen supplementation, ${ }^{4}$ with no noted benefits from the higher oxygen exposure. Two of the three RCTs comparing room air with $100 \%$ oxygen $^{3,5}$ had a higher treatment failure rate (as defined by the studies and noted in Table 1) in their room air groups (only statistically significant in one ${ }^{3}$ ), suggesting that room air is likely not the best initial $\mathrm{FiO}_{2}$ choice in this population. The other recent RCT comparing room air with 100\% oxygen $^{6}$ demonstrated that all babies initially resuscitated with room air required an increase in $\mathrm{FiO}_{2}$ to reach the targeted preductal saturations, again suggesting room air is perhaps not the best initial $\mathrm{FiO}_{2}$ choice. In this study, there was no difference in treatment failure (as defined by the study and noted in Table 1) between the groups, but this may have been due to the inclusion of more mature infants at 32-34 weeks GA; importantly, the study was underpowered, particularly for those infants $<29$ weeks GA, for any clinical outcomes given that the primary outcome was a laboratory-based measurement of oxidative stress. Several upcoming RCTs are using room air as one of their comparison groups and may help determine if, indeed, it should not be used as the initial gas for resuscitation. ${ }^{15}$ Another upcoming 
RCT will compare $30 \%$ and $65 \%$ as the initial gas for resuscitation. ${ }^{21}$

We have reviewed the most recent and relevant evidence for clinical oxygen use in the resuscitation of infants born at $<32$ weeks GA. The heterogeneous outcomes assessed in each respective study hamper any meta-analysis of the RCTs. ${ }^{12}$ Based on our review of these few small RCTs, the best approach at the present time seems to be initiating resuscitation with an initial $\mathrm{FiO}_{2}$ of $30 \%$ and titrating oxygen up or down based on the preductal pulse oximetry. The oxygen should also be titrated if the HR remains $<100$ despite 30 seconds of effective positive-pressure ventilation. The $\mathrm{FiO}_{2}$ should be titrated to match the current recommended "minute by minute" preductal $\mathrm{SpO}_{2}$ targets from the American Heart Association ${ }^{7,11}$ or the original evidence-based data. ${ }^{15,18}$ Additionally, should cardiac output fail to improve (ie, heart rate $<60$ beats per minute) despite adequate ventilation and chest compressions become necessary, the $\mathrm{FiO}_{2}$ should immediately be increased to $100 \%$ based on current recommendations. ${ }^{7}$

In closing, room air may be acceptable as the initial resuscitation gas, but present data suggest it inadequately stabilizes $\mathrm{SpO}_{2}$ levels or the heart rate of infants $<32$ weeks GA. Given the equivalent stabilization of these infants on $30 \%$ or $90 \%$ $\mathrm{FiO}_{2}$ as the initial resuscitation gas, an $\mathrm{FiO}_{2}$ of $30 \%$ appears to be the better choice given the risks of high oxygen exposure. Determination of the ideal initial resuscitation gas and $\mathrm{SpO}_{2}$ targets requires further high quality research assessing both short-term and long-term outcomes.

\section{Disclosure}

The authors declare no conflict of interest in this work.

\section{References}

1. Abdel-Hady H, Nasef N. Respiratory management of the preterm newborn in the delivery room. Research and Reports in Neonatology. 2012;2:39-53.

2. Escrig R, Arruza L, Izquierdo I, et al. Achievement of targeted saturation values in extremely low gestational age neonates resuscitated with low or high oxygen concentrations: a prospective, randomized trial. Pediatrics. 2008;121(5):875-881.
3. Wang CL, Anderson C, Leone TA, Rich W, Govindaswami B, Finer NN. Resuscitation of preterm neonates by using room air or $100 \%$ oxygen. Pediatrics. 2008;121(6):1083-1089.

4. Vento M, Moro M, Escrig R, et al. Preterm resuscitation with low oxygen causes less oxidative stress, inflammation, and chronic lung disease. Pediatrics. 2009;124(3):e439-e449.

5. Rabi Y, Singhal N, Nettel-Aguirre A. Room-air versus oxygen administration for resuscitation of preterm infants: the ROAR study. Pediatrics. 2011;128(2):e374-e381.

6. Kapadia VS, Chalak LF, Sparks JE, Allen JR, Savani RC, Wyckoff MH. Resuscitation of preterm neonates with limited versus high oxygen strategy. Pediatrics. 2013;132(6):e1488-e1496.

7. American Academy of Pediatrics and American Heart Association. Textbook of Neonatal Resuscitation. 6th ed. Elk Grove Village, IL, USA: American Academy of Pediatrics and American Heart Association; 2011

8. Perlman JM, Wyllie J, Kattwinkel J, et al. Part 11: Neonatal resuscitation: 2010 International Consensus on Cardiopulmonary Resuscitation and Emergency Cardiovascular Care Science With Treatment Recommendations. Circulation. 2010;122(16 Suppl 2):S516-S538.

9. Finer N, Saugstad O, Vento M, et al. Use of oxygen for resuscitation of the extremely low birth weight infant. Pediatrics. 2010;125(2):389-391.

10. Vento M. Tailoring oxygen needs of extremely low birth weight infants in the delivery room. Neonatology. 2011;99(4):342-348.

11. Kattwinkel J, Perlman JM, Aziz K, et al. Neonatal resuscitation: 2010 American Heart Association Guidelines for Cardiopulmonary Resuscitation and Emergency Cardiovascular Care. Pediatrics. 2010; 126(5):e1400-e1413.

12. Brown JV, Moe-Byrne T, Harden M, McGuire W. Lower versus higher oxygen concentration for delivery room stabilisation of preterm neonates: systematic review. PLoS One. 2012;7(12):e52033.

13. Wiswell TE. Resuscitation in the delivery room: lung protection from the first breath. Respir Care. 2011;56(9):1360-1367.

14. Finer N, Rich W. Neonatal resuscitation for the preterm infant: evidence versus practice. J Perinatol. 2010;30 Suppl:S57-S66.

15. Dawson JA, Vento M, Finer NN, et al. Managing oxygen therapy during delivery room stabilization of preterm infants. $J$ Pediatr. 2012;160(1):158-161.

16. Vento M, Saugstad OD. Oxygen supplementation in the delivery room: updated information. $J$ Pediatr. 2011;158(Suppl 2):e5-e7.

17. Kamlin CO, O'Donnell CP, Davis PG, Morley CJ. Oxygen saturation in healthy infants immediately after birth. $J$ Pediatr. 2006;148(5): 585-589.

18. Dawson JA, Kamlin CO, Vento M, et al. Defining the reference range for oxygen saturation for infants after birth. Pediatrics. 2010;125(6): e1340-e1347.

19. Richmond S, Wyllie J. European Resuscitation Council Guidelines for Resuscitation 2010 Section 7. Resuscitation of babies at birth Resuscitation. 2010;81(10):1389-1399.

20. Saugstad OD. New guidelines for newborn resuscitation - a critical evaluation. Acta Paediatr. 2011;100(8):1058-1062.

21. Rook D, Schierbeek H, van der Eijk AC, et al. Resuscitation of very preterm infants with $30 \%$ vs $65 \%$ oxygen at birth: study protocol for a randomized controlled trial. Trials. 2012;13:65. 


\section{Authors' reply}

\section{Hesham Abdel-Hady \\ Nehad Nasef}

Neonatal Intensive Care Unit, Mansoura University Children's Hospital, Mansoura, Egypt

Correspondence: Hesham Abdel-Hady

Neonatal Intensive Care Unit, Mansoura University Children's

Hospital, Gomhoria, Street, Mansoura 355I6, Egypt

$\mathrm{Tel}+2000527805 \mathrm{I}$

Fax+20502234092

Email hehady@yahoo.com

\section{Dear editor}

We compliment Moore and Navabi for their updated report on evidence-based choice of the initial fraction of inspired oxygen $\left(\mathrm{FiO}_{2}\right)$ for resuscitation of premature infants $<32$ weeks gestation. These infants often need respiratory support and oxygen supplementation immediately after birth, and adequate oxygenation is essential because both hypoxia and hyperoxia can have detrimental effects. ${ }^{1,2}$

Moore and Navabi correctly point out that studies in preterm infants failed to define the optimal initial $\mathrm{FiO}_{2}$ during resuscitation. A recent meta-analysis ${ }^{3}$ of six randomized controlled trials (RCTs) ${ }^{4-9}$ concluded that there is not sufficient evidence to affirm that the use of lower or higher initial $\mathrm{FiO}_{2}$ in the delivery room for preterm babies confers important benefits or harm. Moreover, none of these trials ${ }^{4-9}$ was actually powered to evaluate important long-term outcomes such as survival without significant neurodevelopmental disability. Until further evidence becomes available, we still believe that the best approach is to initiate a resuscitation with an $\mathrm{FiO}_{2}$ of $30 \%$, thereafter, $\mathrm{FiO}_{2}$ should be titrated according to the pulse oximetry oxygen saturation $\left(\mathrm{SpO}_{2}\right)$ readings with changes in $10 \%$ intervals performed every 30 seconds to allow babies cardio-respiratory response.

Oxygen blenders and pulse oxygen saturation monitors should be used to achieve the balance of administering the $\mathrm{FiO}_{2}$ based on the infant's needs. Using pulse oximetry to guide oxygen therapy in the delivery room is not evidencebased practice. However, the American Heart Association (AHA) $)^{10}$ and the European Resuscitation Council (ERC) $)^{11}$ guidelines advise preductal $\mathrm{SpO}_{2}$ targets for the first 10 minutes after birth, without specifying the gestational age. These targets are based on observational studies of healthy infants not requiring any intervention during their resuscitation. ${ }^{12}$ The AHA guidelines advise a narrow $\mathrm{SpO}_{2}$ target range close to the median values for infants who do not require resuscitation $\left(\mathrm{SpO}_{2}\right.$ target ranges at 1, 2, 3, 4, 5, and 10 minutes after birth are $60 \%-65 \%, 65 \%-70 \%, 70 \%-75 \%$, $75 \%-80 \%, 80 \%-85 \%$, and $85 \%-95 \%$, respectively), while the ERC guidelines prescribe single value $\mathrm{SpO}_{2}$ targets $\left(\mathrm{SpO}_{2}\right.$ of $60 \%, 70 \%, 80 \%, 85 \%$, and $90 \%$ at $2,3,4,5$, and 10 minutes after birth, respectively) these values are closer to the 25th percentile. Recently a group of experts have suggested that the use of the 10th and 50th percentile $\mathrm{SpO}_{2}$ curves of Dawson's nomograms, ${ }^{12}$ as the $\mathrm{SpO}_{2}$ target range may be more appropriate. ${ }^{13}$ Moreover, Dawson's nomograms classified by gestational age may be very useful for the resuscitation team as they allow more accurate target $\mathrm{SpO}_{2}$ to be established according to gestational age. ${ }^{12}$ It is worth noting that the available $\mathrm{SpO}_{2}$ targets are based on observational studies of healthy infants not requiring any intervention during their resuscitation, in a recent study it has been shown that preterm babies and especially females receiving positive pressure and air attain higher saturations earlier than those spontaneously breathing. ${ }^{14}$ Meanwhile, resuscitation team must control the $\mathrm{SpO}_{2}$ adequately, and follow the targets with as little deviation as possible. Recently it was demonstrated that the resuscitation team could effectively maintain $\mathrm{SpO}_{2}$ values within a specific target range during transition using Transitional Oxygen Targeting System (TOTS) plots which record real-time $\mathrm{SpO}_{2}$ values in relation to 10 th and 50th percentile $\mathrm{SpO}_{2}$ curves. ${ }^{15}$

Further appropriately-sized RCTs are needed to define the best initial $\mathrm{FiO}_{2}$ and the appropriate $\mathrm{SpO}_{2}$ range in the delivery room. These trials should measure not only short term but also long-term outcomes. The Targeted Oxygenation in the Resuscitation of Premature Infants and Their Developmental Outcome trial (TO2RPIDO) ${ }^{16}$ is recruiting infants at $\leq 31$ weeks' gestation to compare $100 \%$ oxygen and air as the initial gas for resuscitation, using $\mathrm{SpO}_{2}$ targeting. For the air group, $\mathrm{FiO}_{2}$ is increased if $\mathrm{SpO}_{2}$ is $<65 \%$ by 5 minutes, $<80 \%$ at $5-10$ minutes, and $<85 \%$ thereafter. In the $100 \%$ oxygen group, $\mathrm{FiO}_{2}$ is decreased when $\mathrm{SpO}_{2}>92 \%$. The Study of Room Air Versus 60\% Oxygen for Resuscitation of Premature Infants (PRESOX) ${ }^{17}$ will use targeted oxygen saturation levels over the first 15 to 20 minutes of life to compare a low $(21 \%)$ and a higher initial oxygen $(60 \%)$ level for the resuscitation of preterm infants $<29$ weeks gestation, and will be large enough to evaluate short term outcomes of survival without oxygen at 36 weeks and survival without retinopathy of prematurity, and the long term outcome of survival without significant neurodevelopmental impairment at 2 years of age. 
To summarize, resuscitation in room-air or $100 \%$ oxygen is not recommended for preterm neonates $<32$ weeks gestation. The $\mathrm{FiO}_{2}$ of $30 \%$ apparently enhances successful transition, lowers the oxygen exposure, and diminishes the risk of oxidative damage. $\mathrm{The} \mathrm{FiO}_{2}$ should be titrated according to $\mathrm{SpO}_{2}$ values. Further RCTs are needed to define the best initial $\mathrm{FiO}_{2}$ and the appropriate $\mathrm{SpO}_{2}$ range in the delivery room for preterm infants. These trials should measure not only short term but also long-term outcomes.

\section{Disclosure}

The authors report no conflicts of interest in this communication.

\section{References}

1. Saugstad OD. Oxidative stress in the newborn - a 30-year perspective. Biol Neonate. 2005;88(3):228-236.

2. McColm JR, Cunningham S, Wade J, et al. Hypoxic oxygen fluctuations produce less severe retinopathy than hyperoxic fluctuations in a rat model of retinopathy of prematurity. Pediatr Res. 2004;55(1):107-113.

3. Brown JV, Moe-Byrne T, Harden M, McGuire W. Lower versus higher oxygen concentration for delivery room stabilization of preterm neonates: systematic review. PLoS One. 2012;7(12):e52033.

4. Harling AE, Beresford MW, Vince GS, Bates M, Yoxall CW. Does the use of $50 \%$ oxygen at birth in preterm infants reduce lung injury? Arch Dis Child Fetal Neonatal Ed. 2005;90(5):F401-F405.

5. Saugstad OD, Rootwelt T, Aalen O. Resuscitation of asphyxiated newborn infants with room air or oxygen: an international controlled trial: the Resair 2 study. Pediatrics. 1998;102(1):e1.

6. Lundstrom KE, Pryds O, Greisen G. Oxygen at birth and prolonged cerebral vasoconstriction in preterm infants. Arch Dis Child Fetal Neonatal Ed. 1995;73(2):F81-F86.
7. Vento M, Moro M, Escrig R, et al. Preterm resuscitation with low oxygen causes less oxidative stress, inflammation, and chronic lung disease. Pediatrics. 2009;124(3):e439-e449.

8. Wang CL, Anderson C, Leone TA, Rich W, Govindaswami B, Finer NN. Resuscitation of preterm neonates by using room air or 100\% oxygen. Pediatrics. 2008;121(6):1083-1089.

9. Rabi Y, Singhal N, Nettel-Aguirre A. Room-air versus oxygen administration for resuscitation of preterm infants: the ROAR study. Pediatrics. 2011;128(2):e374-e381.

10. Kattwinkel J, Perlman JM, Aziz K, et al. Neonatal resuscitation: 2010 American Heart Association guidelines for cardiopulmonary resuscitation and emergency cardiovascular care. Pediatrics. 2010;126(5): e1400-e1413.

11. Richmond S, Wyllie J. European Resuscitation Council guidelines for resuscitation 2010 section 7. Resuscitation of babies at birth Resuscitation. 2010;81(10):1389-1399.

12. Dawson JA, Kamlin CO, Vento M, et al. Defining the reference range for oxygen saturation for infants after birth. Pediatrics. 2010;125(6): e1340-e1347.

13. Dawson JA, Vento M, Finer NN, et al. Managing oxygen therapy during delivery room stabilization of preterm infants. J Pediatr. 2012; 160(1):159-161.

14. Vento M, Cubells E, Escobar JJ, et al. Oxygen saturation after birth in preterm infants treated with continuous positive airway pressure and air: assessment of gender differences and comparison with a published nomogram. Arch Dis Child Fetal Neonatal Ed. 2013;98(3):F228-F232.

15. Gandhi B, Rich W, Finer N. Achieving targeted pulse oximetry values in preterm infants in the delivery room. $J$ Pediatr. 2013;163(2) $412-415$.

16. See KC, Oei J, Clark R, Lui K, for the TO2RPIDO Multinational Study Group. Feasibility of a randomized trial of targeted oxygen for the resuscitation of premature infants and their developmental outcome (TO2RPIDO). Journal of Paediatrics and Child Health. 2009;45:A15, Abstract\# A017.

17. Resuscitation of Premature Infants (PRESOX). Available from: http:// clinicaltrials.gov/ct2/show/NCT01773746. Accessed December 26, 2013.
Research and Reports in Neonatology

\section{Publish your work in this journal}

Research and Reports in Neonatology is an international, peer-reviewed, open access journal publishing original research, reports, editorials, reviews and commentaries on neonatal health. The manuscript management system is completely online and includes a very quick and fair

\section{Dovepress}

peer-review system. Visit http://www.dovepress.com/testimonials.php to read real quotes from published authors. 